\title{
Evaluating the challenges and benefits associated with resource planning and leveling in the Kenyan Construction Industry
}

\author{
Shadrack Mutungi Simon* \\ Tutorial Fellow, Department of Construction Management, Jomo Kenyatta University of Agriculture and Technology, \\ (JKUAT), Nairobi, Kenya.
}

Global Journal of Engineering and Technology Advances, 2021, 06(02), 151-158

Publication history: Received on 20 January 2021; revised on 22 February 2021; accepted on 24 February 2021

Article DOI: https://doi.org/10.30574/gjeta.2021.6.2.0027

\begin{abstract}
Resource Planning and Leveling are two critical areas of resource management which need to be implemented by contractors to aid in construction project execution. However, in the process of undertaking these processes in their projects, contractors meet a number of challenges which discourage them from implementing Resource Planning and Leveling. Nonetheless, Resource Planning and Leveling has a number of benefits which may not be known by some contractors. The purpose of this research therefore was to establish and evaluate the challenges and benefits associated with Resource Planning and Leveling. A survey design was adopted by the researcher. A sample of 106 respondents was selected randomly and a response rate of $76 \%$ was achieved. Quantitative data was analysed using descriptive statistics and relative importance index analysis while qualitative data was analysed thematically. Contractors were found to experience serious challenges in their quest to execute Resource Planning and Leveling in their projects. The three most pressing challenges experienced by contractors were found to be: project delays (RII=0.8597); technical incompetence (RII=0.8564); materials shortages or late delivery (RII=0.8390). A number of benefits were found to entice contractors to carry out Resource Planning and Leveling in their projects. The three most significant benefits were: establishing plans for material delivery (RII=0.9215); balanced resources, reducing over allocations or overtime (RII=0.9165) and determining or predicts resources needed (RII=0.9139).
\end{abstract}

Keywords: Resource Planning; Resource Leveling; Challenges, Benefits

\section{Introduction}

The Kenyan construction industry is a key sector within the country's economy and its' level of activity gives an indication of the country's general economic performance (1). It can also be argued that construction industry influences and is also influenced by economic growth in any country. One of the key players in the construction industry is the contractor. Contractors need not only to be efficient but also effective in their resource management. Resource Planning and Leveling are two critical areas of resource management which need to be implemented by contractors to aid in construction project execution. However, in the process of undertaking these processes in their projects, contractors meet a number of challenges which discourage them from implementing Resource Planning and Leveling. Nonetheless, Resource Planning and Leveling has a number of benefits which may lead to efficient project execution if exploited. The purpose of this research therefore was to establish and evaluate the challenges and benefits associated with Resource Planning and Leveling.

\footnotetext{
* Corresponding author: Shadrack Mutungi Simon

Tutorial Fellow, Department of Construction Management, Jomo Kenyatta University of Agriculture and Technology, (JKUAT), Nairobi, Kenya.. 


\section{Literature review}

\subsection{Challenges experienced in Resource Planning \& Leveling}

Many challenges have been cited by authors in both the manufacturing and construction industries as the contributing factors to their lack of practicing structured and formal Resource Planning and Leveling. Some of these factors have also been raised by those who have been carrying out resource planning and management. These include: lengthy payment terms (2); ignorance of network methods to capacity constraints (3); tedious exercise (4); lack of knowledge on how to carry out resource planning and leveling (2); resource unavailability (5); lack of commitment by top level management (6); site storage constraints (7); technical incompetence (2); contractor's project management incapability (8); late honoring of payments' certificates (6); adequacy of plants \& equipment (9); contractor's organizational structure or organizational problems (10); contractors ICT compliance challenges (11); too many variations (12); project complexity and materials shortages or late delivery (13); claims (4); plants, equipment's \& machine breakdown/inadequacy (2); disputes and communications problem (Ubani et al., 2010); poor work definition (13); environmental regulations and inadequate project documentation (15); design deficiencies (16); project risks, uncertainty and delays (5); absenteeism of workers/shortage of craftsmen and increase in prices of materials or labour (14).

\subsection{Benefits of Resource Planning \& Leveling}

Resource Planning and Leveling has quite a number of benefits. These include: balanced resources, reducing over allocations or overtime (17); validates schedule; makes the schedule realistic (8); predicts dates based on information entered. This is based on durations, links and resources assigned (18); determines or predicts resources needed (19); helps maintain the lowest uniform number of employees to perform the work (20); establishing plans for material delivery (18); reducing the daily demand for cash (12); less management attention is required (19); reduced project costs (21); reduced cost of learning (7); improved learning curve (7); enhanced overall organizational strategic planning (9); better view of future projects (10); reduction of errors (22) and increased workers' morale due to guaranteed job security (19)

\section{Methodology}

The researcher adopted a survey research design whereby questionnaires were used to collect data. Out of the 106 questionnaires distributed, 81 were returned. This represented a response rate of $76 \%$ which was deemed adequate for the research.

\section{Data analysis and discussion}

\subsection{Challenges associated with Resource Planning and Leveling}

A number of challenges associated with Resource Planning and Leveling were presented to the respondents to express views on their significance based on a likert scale (5-Strongly Agree; 4- Agree; 3-Undecided; 2-Disagree; 1-Strongly Disagree). The results were presented in the tables below.

As per table 1 above, and based on means, "Technical incompetence" was the most significant with a mean of 4.38 while "Project delays" and "Materials shortages or late delivery" were the second and third most significant with means of 4.32 and 4.26 respectively. The fourth and fifth challenges were "Contract disputes" and "Plants, equipment's \& machine breakdown/inadequacy" with means of 3.94 and 3.93 respectively. "Poor work definition; inadequate project documentation" and "Project risks \& uncertainty" were the sixth and seventh most important factors with means of 3.87 and 3.85 respectively. The eighth and ninth challenges were "Lack of commitment by top level management" and "Tedious exercise" with means of 3.72 and 3.62. The last three challenges were "Contractors ICT compliance challenges", "Absenteeism of workers/shortage of craftsmen" and "Site storage constraints" with means of 3.43, 3.35 and 3.26 respectively.

Low values of standard deviations meant that there was consistency among contractors regarding their views on the perceived challenges. Generally, all the challenges presented to the respondents can be said to be critical since they had an overall mean of 3.8275 as seen in the table 2 below. 
Table 1 Challenges associated with RP\&L (Comparison of Means)

\begin{tabular}{|l|l|l|l|l|l|}
\hline No & & Mean & Std. Deviation & N & Rank \\
\hline 1 & Technical incompetence; lack of knowledge & 4.38 & 0.624 & 68 & 1 \\
\hline 2 & Tedious exercise & 3.62 & 0.962 & 68 & 9 \\
\hline 3 & Materials shortages or late delivery & 4.26 & 0.840 & 68 & 3 \\
\hline 4 & Project delays & 4.32 & 0.657 & 68 & 2 \\
\hline 5 & Lack of commitment by top level management & 3.72 & 1.063 & 68 & 8 \\
\hline 6 & Site storage constraints & 3.26 & 1.060 & 68 & 12 \\
\hline 7 & Project risks \& uncertainty & 3.85 & 0.851 & 68 & 7 \\
\hline 8 & Plants, equipment's \& machine breakdown/inadequacy & 3.93 & 0.816 & 68 & 5 \\
\hline 9 & Poor work definition; inadequate project documentation & 3.87 & 1.091 & 68 & 6 \\
\hline 10 & Contract disputes & 3.94 & 1.006 & 68 & 4 \\
\hline 11 & Absenteeism of workers/shortage of craftsmen & 3.35 & 1.117 & 68 & 11 \\
\hline 12 & Contractors ICT compliance challenges & 3.43 & 1.041 & 68 & 10 \\
\hline
\end{tabular}

Table 2 Challenges associated with RP\&L (Summary of Means)

\begin{tabular}{|l|l|l|l|l|l|l|}
\hline & Mean & Min & Max & Range & Variance & N of Items \\
\hline Item Means & 3.8275 & 3.260 & 4.380 & 1.120 & 0.199 & 12 \\
\hline
\end{tabular}

Table 3 Challenges associated with RP\&L (Relative Importance Index)

\begin{tabular}{|l|l|l|l|l|}
\hline S/No. & & N & RII & Rank \\
\hline 1 & Technical incompetence; lack of knowledge & 78 & 0.8564 & 2 \\
\hline 2 & Tedious exercise & 74 & 0.7108 & 9 \\
\hline 3 & Materials shortages or late delivery & 77 & 0.8390 & 3 \\
\hline 4 & Project delays & 77 & 0.8597 & 1 \\
\hline 5 & Lack of commitment by top level management & 77 & 0.7584 & 8 \\
\hline 6 & Site storage constraints & 78 & 0.6564 & 11 \\
\hline 7 & Project risks \& uncertainty & 76 & 0.7684 & 7 \\
\hline 8 & Plants, equipment's \& machine reakdown/inadequacy & 77 & 0.7922 & 4 \\
\hline 9 & Poor work definition; inadequate project documentation & 77 & 0.7688 & 6 \\
\hline 10 & Contract disputes & 78 & 0.7872 & 5 \\
\hline 11 & Absenteeism of workers/shortage of craftsmen & 78 & 0.6538 & 12 \\
\hline 12 & Contractors ICT compliance challenges & 78 & 0.6692 & 10 \\
\hline
\end{tabular}

The researcher also carried out an analysis of the same challenges using the Relative Importance Index. The results, as per table 3 indicated that the most significant challenge faced by contractors when carrying out Resource Planning and Leveling was "Project delays" with a RII of 0.8597. Other factors in descending order were: "Technical incompetence; lack of knowledge" (RII=0.8564); "Materials shortages or late delivery" (RII=0.8390); "Plants, equipment's \& machine breakdown/inadequacy" (RII=0.7922); "Contract disputes" (RII=0.7872); "Poor work definition; inadequate project documentation" (RII=0.7688); "Project risks \& uncertainty" (RII=0.7684); "Lack of commitment by top level management" (RII=0.7584); "Tedious exercise" (RII=0.7108) "Contractors ICT compliance challenges" (RII=0.6692); "Site storage constraints" (RII=0.6564) and lastly "Absenteeism of workers/shortage of craftsmen" (RII=0.6538). These results indicate that all the respondents' are in agreement that the assessed factors are significant challenges encountered in Resource Planning and Leveling. 
A comparison between the two methods of analysis showed that though technical incompetence was the most significant challenge based on the mean ranking, project delays was the most significant based on the RII ranking. The least significant challenge according to the method of means was site storage constraints while absenteeism of workers was the least significant challenge using the RII analysis. However, both methods of analysis produced the same top three and last three significant challenges though not in the same order.

\subsection{Benefits associated with Resource Planning and Leveling.}

A number of benefits associated with Resource Planning and Leveling and obtained form literature review were presented to the respondents to express views on their significance based on a likert scale (5-Strongly Agree; 4- Agree; 3-Undecided; 2-Disagree; 1-Strongly Disagree). The results were presented in the tables below.

Table 4 Benefits associated with RP\&L (Comparison of Means)

\begin{tabular}{|l|l|l|l|l|l|}
\hline No & \multicolumn{1}{|c|}{ Mean } & Std. Deviation & N & Rank \\
\hline 1 & $\begin{array}{l}\text { Balanced resources, reducing over allocations or } \\
\text { overtime }\end{array}$ & 4.60 & 0.494 & 77 & 2 \\
\hline 2 & Determines or predicts resources needed & 4.58 & 0.522 & 77 & 3 \\
\hline 3 & $\begin{array}{l}\text { Helps maintain the lowest uniform number of } \\
\text { employees to perform the work. }\end{array}$ & 4.31 & 0.782 & 77 \\
\hline 4 & Establishing plans for material delivery. & 4.61 & 0.517 & 77 & 1 \\
\hline 5 & Reduced project costs & 4.26 & 0.834 & 77 & 5 \\
\hline 6 & Reduced cost of learning and improved learning curve & 3.86 & 0.823 & 77 & 9 \\
\hline 7 & Enhanced overall organizational strategic planning & 4.26 & 0.696 & 77 & 5 \\
\hline 8 & Reduction of errors & 4.12 & 0.873 & 77 & 7 \\
\hline 9 & $\begin{array}{l}\text { Increased workers' morale due to guaranteed job } \\
\text { security }\end{array}$ & 3.95 & 0.916 & 77 & 8 \\
\hline
\end{tabular}

The table 4 above indicated that "Establishing plans for material delivery" was the most significant benefit with a mean of 4.61 while "Balanced resources, reducing over allocations or overtime" and "Determines or predicts resources needed" were the second and third most significant with means of 4.60 and 4.58 respectively. The fourth and fifth challenges were "Helps maintain the lowest uniform number of employees to perform the work", "Reduced project costs" and "Enhanced overall organizational strategic planning" with means of 4.31 and 4.26 respectively. "Reduction of errors" and "Increased workers' morale due to guaranteed job security" were the seventh and eighth most important factors with means of 4.12 and 3.95 respectively. The last benefit based on this method of ranking was "Reduced cost of learning and improved learning curve" with a mean of 3.86. These results revealed that the assessed factors were unanimously acknowledged by majority of contractors to be significant benefits for Resource Planning and Leveling. This is further supported by table 5 below which shows an overall mean of 4.2833 of all the assessed benefits.

Table 4 Benefits associated with RP\&L (Summary of Means)

\begin{tabular}{|l|l|l|l|l|l|l|}
\hline & Mean & Min & Max & Range & Variance & N of Items \\
\hline Item Means & 4.2833 & 3.860 & 4.600 & 0.740 & 0.199 & 9 \\
\hline
\end{tabular}


Table 6 Benefits associated with RP\&L (Relative Importance Index)

\begin{tabular}{|c|c|c|c|c|}
\hline No & & $\mathbf{N}$ & RII & Rank \\
\hline 1 & Balanced resources, reducing over allocations or overtime & 79 & 0.9165 & 2 \\
\hline 2 & Determines or predicts resources needed & 79 & 0.9139 & 3 \\
\hline 3 & $\begin{array}{l}\text { Helps maintain the lowest uniform number of employees to perform the } \\
\text { work. }\end{array}$ & 79 & 0.8557 & 4 \\
\hline 4 & Establishing plans for material delivery. & 79 & 0.9215 & 1 \\
\hline 5 & Reduced project costs & 79 & 0.8456 & 6 \\
\hline 6 & Reduced cost of learning and improved learning curve & 78 & 0.7667 & 9 \\
\hline 7 & Enhanced overall organizational strategic planning & 78 & 0.8513 & 5 \\
\hline 8 & Reduction of errors & 78 & 0.8256 & 7 \\
\hline 9 & Increased workers' morale due to guaranteed job security & 79 & 0.7772 & 8 \\
\hline
\end{tabular}

The researcher further carried out an analysis of the same benefits using the Relative Importance Index. The results, as per table 6 above indicated that the most significant benefit realized by contractors when carrying out Resource Planning and Leveling was "Establishing plans for material delivery" with a RII of 0.9215. Other benefits in descending order were: "Balanced resources, reducing over allocations or overtime" (RII=0.9165); "Determines or predicts resources needed" (RII=0.9139); "Helps maintain the lowest uniform number of employees to perform the work" (RII=0. 0.8557); "Enhanced overall organizational strategic planning" (RII=0. 0.8513); "Reduced project costs" (RII=0.8456); "Reduction of errors" (RII=0.8256); "Increased workers' morale due to guaranteed job security" (RII=0.7772) and lastly "Reduced cost of learning and improved learning curve" (RII=0.7667) These results indicate that all the respondents' are in agreement that the assessed factors are significant benefits realized in Resource Planning and Leveling.

A comparison between the two methods of analysis showed similar ranking in the first four and last three benefits presented to the respondents. While the method of means produced a tie in the fifth position, the RII ranking did not.

\subsection{Overcoming challenges associated with RP\&L}

Respondents made 97 suggestions as possible solutions to overcoming challenges associated with Resource Planning and Leveling (RP\&L). The researcher critically reviewed these solutions and grouped them into themes namely: technical; financial; resource management; project planning and control; top management involvement; communication and others. The classification of respondents' suggestions was as follows: technical, 50 (52\%); financial, 3 (3\%); resource management, 7 (7\%); project planning and control, 14 (14\%); top management involvement, 7 (7\%); communication, 3 (3\%) and others, $13(13 \%)$.

\subsubsection{Technical factors}

As suggested by Chonge (2016), technical capability involves the availability of technical personnel to execute works and the availability of plant and equipment to aid in the process of undertaking the works. The researcher established 57 suggestions which could be grouped under technical issues. Out of these suggestions 20 of them (33\%) were directly related to technical capacity in terms of personnel. Majority of these suggestions touched on staff training and engagement of technically qualified employees to carry out works.

The following is a list of all suggested solutions proposed by respondents and listed by the researcher under technical factors. All these factors seemed to be addressing the first challenge (technical incompetence) in the questionnaire presented to the respondents.

Some of the solutions under this category include: Integration of all levels of employees in the resource planning and train them in preparation of the same, both manually and using software; Employment of skilled workers with ability to use PM tools such as MS project; Employment of trained qualified construction managers to run sites; Ensuring involvement of qualified professionals in the project delivery process who appreciate the importance of resource 
planning and leveling; Engagement of a qualified person who understands the construction processes and concepts, and has the technical know-how to be doing resource planning and levelling; Staff training on planning software; Retaining of qualified personnel and operatives for future projects; Establishment of an effective training program.

Other factors include: Document completed projects accordingly and use them as case studies to predict and forecast similar projects accordingly; Using simple tools such as site records and daily updates opposed to MS Project; Quality control through detailed instructions on output; Competent site manager and regular site visits for self-assessment; Improve ICT skills in contractor firms to learn resource planning tools; Delegate the role of resource planning and levelling to specific people in a firm as this will make it less tedious since it will be the duty of the specific persons and not everyone's responsibility; Use of Project Management Software such as MS Project in resource planning and levelling to make it less tedious; Consideration of several alternative analyses when doing resource planning and levelling; Critical path method; Optimizing method; Incorporating project managers in construction companies with administrators following up decisions made by project managers; Increased involvement by project coordinators and site agents in planning; Proper documentation of site progress reports; Proper delegation of works; Well defined scope of project at the commencing stage of project and Scenario forecasts.

The following solutions were also suggested by the respondents in this study: Increased I.C.T Compliance; Disclosure of project details to the project manager especially resources as it gives a better analysis of possible ways to solve shortages in resource; Undertake resource mapping; Keenly going through the project scope and identify all resources involved and have them in good time for every project task/activity; Developing a detailed risk, resource, financial and quality plan during project planning phase; strategizing on principles for developing, utilizing and conserving human resources Identification of strengths and weaknesses of labor force; Overall participation by core project management team members to ensure all aspects of the project are taken care of; Proper project definition to ascertain the exact resources requirements and especially where resources are shared among several projects; Companies to come up with their own systems of resource planning and leveling, educate and make strict follow-ups of the same to their employees.

\subsubsection{Financial factors}

The following suggestions were made by respondents as possible solutions to financial related challenges: Prompt payment to the contractor; Minimizing delays in payment of workers and also guarantee the job security so as to increase their morale; Develop financial management and budgetary skills and finally giving incentives to workers.

\subsubsection{Resource Management factors}

The respondents highlighted the following to be solutions to problems related to resource management issues: Adherence to the resource leveling and planning strategies set; Having surplus materials (which can still be used in future areas of project) on site for unseen; Reliance on multiple sources for materials; Ensuring availability of resources at all times for effective planning; Frequent servicing of equipment and machines to avoid unnecessary breakdowns and having sufficient site managers and supervisors.

\subsubsection{Project planning and control factors}

A number of factors listed by the respondents were grouped into project planning and control factors category. These included: Proper coordination between the drafters and implementers; Ensuring there is full cycle cooperation during resource planning among various departments in a contractor's office such as procurement, accounts, project management and site team; Keeping track of the resource graph as the project continues to level where necessary; Constant vigilance in monitoring project schedules; Consistent periodic reviews on the trends and immediate necessary actions; Follow up in planning so that it's not all in vain; Timely planning; Breaking down the tasks into simple actionable activities for foremen on site for ease of execution and follow up; Grouping tasks that require similar resources; Breakdown of the whole project into workable, realistic, strategic and sequential work breakdown structure for easy planning and levelling of resources; Developing adequate project brief in early stages of the project; Proper planning; Having contingency plans and advance planning of activities in future using the programme of works.

\subsubsection{Management related factors}

Factors related to management involvement included: Ensuring there is full cooperation and commitment by management; Sensitize top level management on the importance of investing in a program of works and organized resource allocation reports; Involve clients and top management and administration in the RP\&L process. This way, it will be adapted by all at any level of management thus making it easy for the whole firm to adapt these techniques; Ensure that the top management are skilled and have knowledge about the work to be done. 


\subsubsection{Communication related factors}

Factors categorised under communication included: Raising any issues immediately they occur and addressing them with all parties to come up with solution and creating more awareness about the subject matter.

\subsubsection{Other factors}

Factors which could not be grouped in any of the above themes included: Ensuring that resource planning is carried out before projects, during the projects and after the projects to ensure it is effective; The resource planning should be conclusive and carried out on all areas that affect the projects; Prepare early enough for the project to be undertaken; Good site records on resources; Proper procurement schedules; Consistency during implementation; Planning earlier before site activities commence; Increased awareness within all industry practitioners on the importance, and hence emphasis on Resource Planning and Leveling; Emphasis on incorporation of the same at the early stages of project conception, scope identification and planning to enable benefits trickle down from the very beginning of project implementation; Introduce course units on the same at undergraduate level; Mandatory and statutory enforcement from local and national authorities; and sensitization of construction industry players.

\section{Conclusion}

Contractors face a number of challenges when undertaking Resource Planning and Leveling. The three most severe challenges are; project delays, technical incompetence and materials shortages or late delivery. Contractors get a number of benefits from carrying out Resource Planning and Leveling. The three most important benefits are; enables establishing plans for material delivery; balanced resources, reducing over allocations or overtime. Contractors are aware of the solutions available for overcoming challenges associated with Resource Planning and Leveling.

\section{Recommendations}

Site records should be well kept and used as tools for monitoring the process of resource leveling. Projects should be properly documented before the construction phase. This will enable project planners to estimate accurately the project resource needs and prepare a reliable resource plan. Contractors should document completed projects accordingly and use them as case studies to predict and forecast similar projects accordingly. In todays' changing times in terms of technology, contractors should work towards improving their ICT competence. They should also train their employees on planning software such as MS. Project.

\section{Compliance with ethical standards}

\section{Acknowledgments}

I would like to acknowledge all the respondents who participated in this research.

\section{Disclosure of conflict of interest}

I would like to declare that there's no conflict of interest with regard to this paper.

\section{References}

[1] Ndaiga H. Overview: Kenya Construction Industry [Internet]. 2014 [cited 2016 Jan 4].

[2] Pennypacker J. Resource management challenges: A benchmark of current business practices. Havertown; 2009.

[3] Bakouros, Yannis, Kelessidis V. Project Management. 2000; 0-32.

[4] Aitken R-LKA. Human resources planning : issues and methods table of contents. Data Decis Mak Proj [Internet]. 1993; 1-37.

[5] Mendoza C. Resource Planning and Resource Allocation in the Construction Industry. University of Florida. 1995.

[6] Badawiyeh BH. The Effect of Planning and Resource Leveling. The British University in Dubai. 2010.

[7] Bandelloni M, Tucci M, Rinaldi R. Optimal resource leveling using non-serial dynamic programming. Eur J Oper Res Eur J Oper Res. 1994; 78(2): 162-77. 
[8] Suttle R. The Advantages and Disadvantages of Resource Constrained Projects [Internet]. 2016 [cited 2016 Jul 25].

[9] Dubey A. Resource Levelling for a Construction Project. 2015; 12(4): 5-11.

[10] Easa SM. Resource Leveling in Construction by Optimization. J Constr Eng Manag. 1989; 115(2): 302-16.

[11] Garmsiri M, Abassi MR. Resource leveling scheduling by an ant colony-based model. 2012; 8(1): 1.

[12] MacKenzie S. Resource Management Maturity Model Benefits [Internet]. 2013 [cited 2016 Jul 25].

[13] Ibrahim II. Project Planning in Construction Procurement: The Case of Nigerian Indigenous Contractors. Jomo Kenyatta University of Agriculture \& Technology. 2014.

[14] Ubani EC, Nwachukwu CC, Nwokonkwo OC. Variation Factors of Project Plan and Their Contributions to Project Failure in Nigeria. Am J Soc Manag Sci. 2010; 1(2): 141-9.

[15] Joshi R, Patil PVZ. Resource Scheduling of Construction Project : Case Study. 2015; 4(5): 563-8.

[16] Kastor A, Sirakoulis K. The effectiveness of resource levelling tools for Resource Constraint Project Scheduling Problem. Int J Proj Manag [Internet]. 2009; 27(5): 493-500.

[17] Nagaraju SK, Reddy BS, Chaudhuri AR. Resource Management in Construction Projects - a case study. Eng Sci Technol An Int J. 2012; 2(4): 660-5.

[18] Tawalare A, Lalwani R. Resource Leveling in Construction Projects using Re- Modified Minimum Moment Approach. 2012; 6(2): 733-5.

[19] Singh A. Benefits of Implementing a Resource Planning Software in your Organization [Internet]. 2013 [cited 2016 Jul 25].

[20] Wilkens T. Fundamentals of Scheduling \& Resource Leveling. 2006 ; 1-7.

[21] Akpan EOP. Resource smoothing: a cost minimization approach. J Prod Plan Control. 2000; 11(8): 775-80.

[22] Fathi H, Afshar A. Multiple Resource Constraint Time-Cost-Resource Optimization Using Genetic Algorithm. 2008; 1990: 42-50.

[23] Chonge MW. An Investigation of the Factors influencing the Performance of Contractors in Kenya. Jomo Kenyatta University of Agriculture and Technology. 2016. 